\title{
Features of determining the nonmanufacturing premises comfort level by the integrated microclimate quality criteria
}

\author{
V.V. Buhmirov and M.V. Prorokova \\ Ivanovo State Power University named by V. I. Lenin, 153003 Ivanovo, Russia
}

\begin{abstract}
The method of determining a microclimate comfort level have been developed, taking into account the main parameters influencing the microclimate in residential, public and administration buildings, their mutual influence on the comfort level, and air quality.
\end{abstract}

\section{Introduction}

The policy of "cheap energy sources" conducted in the XX century, as well as the lack of regulatory requirements to buildings enclosing structures characteristics has led to the fact that the power supply of residential, public and administrative buildings in Russia is one of the most energy-intensive in the world [1]. Currently, one of the priority directions of science, engineering and technology development is energy saving and energy efficiency [2]. As the analysis of energy inspection results shows, buildings constructed before 2000, have significant potential for saving energy resources. Investigations show that more than $30 \%$ of saving potential is concentrated in municipal engineering systems and up to $70 \%$ - in the buildings and structures construction [3]. For this reason, in nonmanufacturing buildings the most often energy saving measures are implemented, aimed at changing the external enclosures design features, such as windows replacement by PVC glazed windows, thermal insulation apposition, entrance doors and gates replacement to reduce the cold air income etc. As the implementation practice shows, the introduced measures can actually be able to provide the energy consumption reduce for heating buildings. However, the significant disadvantage of energy saving measures listed above is the fact, that the energy saving achieved by reducing heat losses due to sealing the building. For objects with natural ventilation the reduce of fresh air inflow due to infiltration can lead to indoor air quality deterioration, which in turn causes the reduce of people performance indoors, and the occurrence of "chronic fatigue syndrome". Eliminating the negative effect of sealing the building requires considerable investment, which can be more than savings obtained from the energy consumption reduction.

Obviously, the microclimate quality and comfort evaluation is extremely urgent before the energy saving measures introduction. Among the thermal parameters defining the premises microclimate and affecting human performance and health, five the most important can be distinguished: the temperature, air mobility and its relative humidity, the amount of thermal radiation and enclosing surfaces temperature. The methods for determining these parameters and their valid values for different

\footnotetext{
${ }^{a}$ Corresponding author: buhmirov@tot.ispu.ru
}

This is an Open Access article distributed under the terms of the Creative Commons Attribution License 4.0, which permits unrestricted use, distribution, and reproduction in any medium, provided the original work is properly cited. 
Table 1. Microclimate comfort level.

\begin{tabular}{|c|l|}
\hline$W$ & Comfort degree \\
\hline$>-0,30$ & cold, uncomfortable \\
\hline$-0,30 \div-0,65$ & cool, slightly uncomfortable \\
\hline$-0,65 \div 1$ & cool, but comfortable \\
\hline 1 & comfortable \\
\hline $0,65 \div 1$ & warm, but comfortable \\
\hline $0,30 \div 0,65$ & warm, slightly uncomfortable \\
\hline$<0,30$ & hot, uncomfortable \\
\hline
\end{tabular}

premises and works types are presented in the regulations. However, the significant disadvantages of premises comfort determination by separate parameters are: firstly, neglect the parameters mutual influence, secondly, the actual neglect the air quality. Considering the listed above disadvantages of existing methods for determining the microclimate quality, a new method has been developed in Ivanovo State Power University (ISPU) for determining comfort and microclimate, using complex index, taking into account the main factors affecting the human body.

\section{Results and discussion}

The method is based on determining the human thermal state comfort coefficient, based on the thermal balance equation components calculation with the introduction of amendments to the radiation fluxes asymmetry, radiation cooling and air quality. Air quality is determined by the carbon dioxide content level, because despite the popular opinion, the reason for human performance decline is not the oxygen concentration decrease, but the rapid growth of carbon dioxide concentration in an enclosed space. [4]

The comfort level $W$ in the ISPU method is defined by the expression:

$$
W=k_{1} \cdot k_{2} \cdot k_{3} \cdot k_{4},
$$

where $k_{1}$ - human thermal state comfort coefficient; varies from 1 to 0 : the value of 1 corresponds to a comfortable human state, 0 - total comfort absence; can have a positive (with heat excess) and negative (with a lack of heat) value;

$k_{2}$ - the coefficient of influence on the radiation cooling comfort, ranged from 1 to 0.9: the value of 1 corresponds to a comfortable human state, 0.9 - the reduced comfort level due to the influence of radiation cooling;

$k_{3}$ - the coefficient, taking into account the impact on the comfort from asymmetry thermal radiation, ranged from 1 to 0.7 : the value of 1 corresponds to a comfortable human state, 0.7 - the reduced comfort level due to the influence of radiation fluxes asymmetry;

$k_{4}$ - the air quality index corresponding to standards established by GOST 30494-2011 [5]; ranges from 1 to 0.5 : the value of 1 corresponds to the high air quality 0.5 - the low air quality.

The comfort degree depending on the comfort level $W$ is defined by Table 1 .

\section{Conclusion}

The originality of the developed in ISPU determining the comfort level method is in the accounting the main parameters, influencing the microclimate in premises of residential, public and administrative buildings and their mutual influence on the comfort level and the air quality. This method of evaluating the microclimate quality can be applied in the design and configuration of heating systems, ventilation and air conditioning of buildings to meet energy saving and energy efficiency requirements, and also allows to add new coefficients at the comfort level calculation, taking into account the perception of microclimatic parameters by different gender groups. 


\section{References}

[1] Energy saving in housing: Training and practical guide, under ed. of L.V. Primak, L.N. Chernyshov (Akademic project: Alma Mater, Moscow, 2011) [in Russian]

[2] RF Presidential Decree of July 7, 2011 N 899, Approval of the priority directions of science, technology and engineering in the Russian Federation and the list of critical technologies of the Russian Federation (Kremlin, Moscow, 2011) [in Russian]

[3] V.V. Buhmirov, O.N. Mahov, M.V. Prorokova, The results of energy audit of public institutions buildings and structures, Collection of scientific works of the international scientific-practical conference "State and prospects of electric technologies development", XVII Benardosovskie reading (FSBEI HPO ISPU, Ivanovo, 2013) [in Russian]

[4] V.V. Buhmirov, O.N. Mahov, M.V. Prorokova, Microclimate parameters affecting the health and performance, Collection of materials of Interuniversity Scientific Conference of graduate students and students with international participation "Young scientists - to the development of textile industry cluster" (SEARCH -2014) (Ivanov State Polytechnic university, Ivanovo, 2014) [in Russian]

[5] GOST 30494-2011, Residential and public buildings. The microclimate parameters in premises [in Russian] 